\title{
La producción de noticias en medios escritos y televisivos de El Salvador
}

\author{
JAVIER URREA CuÉlLAR \\ Politólogo \\ Pontificia Universidad Javeriana \\ Colombia
}

El presente artículo es un avance de una investigación sobre la construcción de noticias en los medios escritos y televisivos de El Salvador'. Para ello se observaron las rutinas de producción de los reportajes políticos elaborados en los siguientes medios de comunicación: $E l$ Diario de Hoy, La Prensa Gráfica y Canal 33. Nos motiva aquí conocer las rutinas del proceso productivo de la noticia, describir sus etapas, identificar los actores que intervienen en cada una de estas fases y observar los criterios de valoración que convierten los acontecimientos en noticia. El artículo comienza describiendo los rasgos fundamentales que distinguen al acontecimiento y la noticia, luego se comentan las experiencias en cada uno de los medios observados y finalmente se concluye sobre las rutinas de producción de noticias, basándonos en las experiencias que dejó el trabajo de campo. 


\section{La problemática: ¿quién y cómo se decide qué deber ser noticia?}

Son los medios masivos de comunicación los que se encargan de suministrarnos información; a través de ellos nos enteramos sobre lo que está sucediendo, nos comunicamos con otros actores o simplemente conocemos y observamos la realidad que día a día se nos presenta.

La capacidad de los medios para asignar importancia a determinados temas en la agenda pública los convierte en constructores de la realidad, no sólo la describen, sino que también nos proporcionan claves para interpretarla; sin embargo, la información que recibimos acerca de esa realidad nunca es completa, los mensajes emitidos por los medios de comunicación, antes de llegar a nuestros sentidos, sufren una serie de controles, modificaciones y distorsiones que no se pueden eludir.

Son varios los estudios que se han hecho sobre el contenido y los efectos del mensaje periodístico ${ }^{2}$; no obstante, las nuevas metodologías de investigación y de análisis de comunicación política centran su objeto de estudio en la labor de los emisores y los procesos de producción del mensaje. Nos interesa aquí comprender y explicar el proceso de producción de noticias en medios de comunicación escritos y televisivos de EI Salvador.

Los estudios sobre la construcción de la noticia han dejado de enfocar sus explicaciones sobre el contenido y los efectos del mensaje periodístico en la audiencia (el qué, a quién y con qué efecto) para pasar a las investigaciones que tienen como objeto de estudio la labor de los emisores y los procesos de producción (quién y cómo).

Las investigaciones realizadas sobre la construcción de la noticia nos ofrecen explicaciones dirigidas en dos líneas: la sociología de las profesiones; es decir, el estudio de la cultura profesional, la ética, los valores y las creencias del periodista; y los procesos de producción de la noticia, los cuales explican las rutinas periodísticas en el momento de construir la noticia.

La construcción de la noticia articula varias fases, no obstante, en cada una de ellas existe una selección de la información. También se le conoce como gatekeeping o "cuidado de la puerta o del acceso"; se le denomina así, porque en cada etapa se escoge y extrae información. Por su lado, la valoración, verificación, interpretación y materializa- 
ción de dicha información abarca el proceso productivo completo y se le conoce como newsmaking (cuadro 1).

\section{Cuadro 1. Etapas en la construcción de la noticia}

\section{Fases del newsmaking}

\begin{tabular}{|c|c|}
\hline & _ Fase 1 _ \\
\hline \multirow{2}{*}{$\begin{array}{l}\text { Valoración del acontecimiento } \\
\text { Recopilación y } \\
\text { (también se analiza la conexión } \\
\text { del hecho con las fuentes) }\end{array}$} & Selección \\
\hline & — Fase 2 \\
\hline \multirow[t]{2}{*}{$\begin{array}{l}\text { - Ampliación, verificación e } \\
\text { interpretación de los hechos }\end{array}$} & $\begin{array}{l}\text { Redacción } \\
\text { Edición }\end{array}$ \\
\hline & _Fase 3 \\
\hline $\begin{array}{l}\text { Forma en que los valores que } \\
\text { que marcan en el hecho son } \\
\text { procesados como noticia }\end{array}$ & Realización \\
\hline - Materialización de la noticia & Presentación \\
\hline
\end{tabular}

Elaboración propia con base en Luzón (1998) y Martini (2000).

La selección de la información es realizada por una serie de actores que dejan circular con fluidez alguna información y evitan que se filtre información indeseada, se les llama gatekeepers o "porteros". En cada una de las etapas los gatekeepers deciden sobre lo que debe ser y no deber ser noticia. Son precisamente los reporteros, fotógrafos, camarógrafos, redactores, editores, diseñadores, productores, jefes o gerentes de información y directores de los medios, quienes actúan como nudos o barreras en el proceso de circulación del mensaje informativo. 
En el presente trabajo, no solamente se intenta identificar quiénes seleccionan la información, sino también observar cómo lo hacen, bajo qué criterios y qué rutinas. Se utilizó una metodología de investigación cualitativa, que a través de la observación no participativa nos permitió comprender y explicar el proceso de producción de reportajes políticos en las revistas de opinión "Enfoques" y "Vértice" de los periódicos salvadoreños La Prensa Gráfica y El Diario de Hoy, respectivamente; y del programa televisivo "Emisión Especial" del Canal 33.

El artículo comienza presentando las características fundamentales que reconocen a un acontecimiento y los valores que lo convierten en noticia, luego se describen tres experiencias sobre la construcción de reportajes políticos en los mass media y finalmente se hacen unas conclusiones sobre la construcción de noticias y las rutinas implícitas de producción en los medios de comunicación mencionados en el párrafo anterior.

\section{El acontecimiento: una variación en el sistema}

El acontecimiento es una ruptura en el ámbito público o privado, que señala una diferencia sobre algo que es uniforme, se define por efectos de tiempo y espacio, y tiene sentido cuando se relaciona con los sujetos sociales (Martini, 2000). Toda noticia, antes de llegar a serlo, comienza por ser un acontecimiento; dicho de otro modo, el proceso de producción de la noticia se inicia a partir de un suceso o un hecho. En los medios de comunicación, el acontecimiento periodístico reúne tres elementos esenciales: la variación en el sistema, la comunicabilidad del suceso y la implicación de los sujetos (Rodrigo Alsina, 1989).

La variación del sistema es todo aquello que supone la ruptura de la norma. El tiempo, el espectáculo y la imprevisión en el acontecimiento provocan variaciones dentro del sistema. La rapidez del acontecimiento significa variación que se da en el tiempo, el hecho aparece y varía rápidamente; cuando el acontecimiento no varía con el paso del tiempo, simplemente caduca y se convierte en algo normal. Otra de las características de la variación es la espectacularidad, en cuanto más anormal y ordinario sea el suceso, mayor será la ruptura en el sistema y más espectacular será el acontecimiento. La variación también se 
puede dar por la imprevisión del hecho, los acontecimientos que no se esperan o no se logran prever marcan una diferencia, causando la ruptura del sistema.

La comunicabilidad del suceso cobra sentido por su relación con el sistema. El acontecimiento periodístico es un hecho social, el cual se $\mathrm{da}$ a conocer al público en forma de noticia a través de los medios de comunicación. Lo que no es comunicable no es noticia y por lo tanto deja de ser acontecimiento tanto para los medios de comunicación como para el público. Dicho de otra forma, los medios construyen la noticia dándole publicidad a los acontecimientos, publicidad que se da a través de la comunicabilidad del hecho por medio de la transmisión escrita o electrónica.

Los mensajes periodísticos se realizan para incidir sobre el destinatario, con base en la implicación que tiene el mensaje sobre quien lo pueda recibir, esta implicación en los sujetos se puede observar bajo dos perspectivas: la implicación sobre el destinatario y la implicación que presupone el periodista que produce la noticia.

La implicación que tiene el acontecimiento sobre el público se da con relación a un sujeto específico. El individuo de manera personal y subjetiva le otorga mayor implicación a determinadas noticias, esta implicación puede ser directa o indirecta. Podemos establecer que algunos individuos perciben unos temas como más importantes que otros, no obstante las noticias denotan diferentes niveles de implicación (Rodrigo Alsina, 1989):

1. Implicación directa y personal. Se refiere a aquellas noticias que afectan directamente la vida cotidiana del individuo.

2. Implicación directa y no personal. Afectan directamente las emociones o ideologías del individuo, mas no tienen relevancia importante en su vida cotidiana.

3. Implicación indirecta. No afecta directamente la vida del individuo, sin embargo, percibe la noticia como algo que sucedió en otro lugar, en otro tiempo y a otras personas.

4. Sin implicación. El individuo se siente indiferente a la información recibida.

Otro tipo de implicación es aquella que los medios de comunicación le otorgan al acontecimiento. Esta implicación es fundamental en

La producción de noticias en medios escritos y televisivos de El Salvador 
el momento de valorar a un acontecimiento como noticia, de tal forma que las implicaciones se traducen en criterios que utilizan aquellas personas que intervienen en el proceso de producción de la noticia. La selección y clasificación de los acontecimientos que serán noticia se sustentan en la relación que tienen los sucesos con el público y con las fuentes.

\section{La noticia: criterios de selección}

"La selección de la información se hace a través de los valores que hacen noticiable a un acontecimiento y su conexión con las fuentes”. (Martini, 2000). Los criterios del gatekeeper son los que estructuran y construyen la noticia ${ }^{3}$, dicho de otro modo, son ellos quienes deciden qué es noticia y qué no lo es. Según Martini, existen una serie de criterios habituales que permiten identificar qué hechos se pueden convertir en noticia, ya sea por la característica del acontecimiento o por el efecto que éste pueda tener sobre la audiencia y sobre otros medios.

Según los efectos que un acontecimiento puede tener sobre la sociedad, los criterios más importantes son:

- La novedad: indica variación en el sistema, existencia de un nuevo acontecimiento que marca un cambio con respecto a la noticia anterior.

- La originalidad, imprevisibilidad e ineditismo: refuerzan la novedad de los hechos, provocan curiosidad, inquietud. Un acontecimiento original es noticia porque es más novedoso, un hecho imprevisible genera conmoción, inseguridad, amenaza.

- La evolución futura de los acontecimientos: indica el significado que el hecho adquiere respecto a las expectativas de la sociedad, ya sea porque se trate de un acontecimiento que debe resolverse o tenga un desarrollo secuencial (una noticia es más noticia si se puede construir información a partir de ella durante varios días).

- El grado de importancia y de gravedad de un acontecimiento, se mide en la incidencia que pueda tener sobre la vida de la sociedad en el presente, en el futuro o en términos de conmoción. El impacto del acontecimiento sobre el interés nacional o local. Las noticias nacionales pesan más en principio, a menos que las internacionales se refieran a hechos que comprometen la nación (guerras, catástro- 
fes, amenazas globales, etc.). Las locales son más importantes cuando afectan gran número de personas y tienen consecuencias sobre el futuro de la comunidad.

- La proximidad geográfica de un hecho se conecta con el interés del público. En cuanto más cerca del público ocurre el acontecimiento, más noticiable es. La proximidad y cercanía se enlaza generalmente con hechos graves o peligrosos.

- La magnitud de personas o lugares implicados se relaciona con el público al cual va dirigida la noticia e implica gravedad en términos cualitativos y de efectos sobre la sociedad. Un hecho es noticia si afecta a muchas personas o ámbitos geográficos.

- La jerarquía de los personajes implicados en un acontecimiento, recurriendo a las apariciones de figuras públicas o personajes reconocidos. Muchas veces son el comentario en la información. Pero también adquieren valor aquellos personajes del común que despiertan el interés o simpatía del público.

- La inclusión de desplazamientos resulta significativa para que un hecho sea noticia. Se trata del cambio de posición y trayectorias de conjuntos de personas (manifestaciones, procesiones) o individuos públicos reconocidos (viajes del presidente, artistas, famosos).

Según las cualidades del acontecimiento, los criterios más importantes para que un hecho sea noticia, son:

- La comprensión e inteligibilidad de un hecho impiden la confusión. Cuando un acontecimiento no es comprensible se suele descartar o esperar a obtener mayor información a través de las fuentes.

- La credibilidad construye un dato confiable, mientras que un hecho de escasa credibilidad obliga a realizar complejas operaciones de explicación y legitimación. La credibilidad de una noticia está más ligada a la fuente que la emite que a la verosimilitud del acontecimiento, por lo que un hecho poco verosímil puede legitimarse si la fuente cuenta con el reconocimiento público.

- La brevedad se relaciona con las características anteriores, y consiste en la posibilidad de construir una noticia en pocas líneas o al menos de manera directa. 
- La periodicidad facilita la labor periodística. Los hechos que son habituales o tienen apariciones periódicas en los medios son más fáciles de construir e interpretar por el público. Posibilitan una mayor comprensión y permiten recurrir a interpretaciones de especialistas o figuras públicas.

- La exclusividad o primicia captura la novedad antes de que otros lo hagan, implicando la capacidad para contactar fuentes legítimas. Un acontecimiento también obtiene reconocimiento cuando es comunicado como primicia exclusiva de otro medio.

- El sensacionalismo es un criterio utilizado por bastantes medios. Implica que un acontecimiento es noticia en cuanto representa una desviación o ruptura habitual de las cosas, lo que hace que lo más negativo o terrible sea lo más noticiable. Las malas noticias son las buenas noticias, porque permiten la construcción en términos de color o sensacionalismo.

En síntesis, existen una serie de criterios habituales que se utilizan en la labor periodística. Todos los valores anteriores funcionan en conjunto, sin embargo, algunos acontecimientos, como los actos de gobierno, reúnen las características necesarias para ser noticia sin necesidad de pasar por unos criterios de selección implícitos en las rutinas de trabajo.

\section{La investigación: un estudio de tipo cualitativo}

Esta investigación fue realizada durante los meses de abril, mayo y junio del año 2003, en los lugares de trabajo y redacción de El Diario de Hoy, La Prensa Gráfica y Canal 33 de El Salvador. El presente análisis pretende convertirse en un instrumento útil y de conocimiento para los estudiantes, profesores, profesionales de la comunicación y población en general, que deseen explorar desde la práctica junto con la teoría, los procesos de producción periodísticos. Se trata de investigar lo que no se ha investigado sobre los medios de comunicación de esta nación y revisar con una óptica diferente lo que ya se ha dicho acerca del tema, desde luego, aplicado al caso salvadoreño. Además, se constituye en un punto de partida para el análisis del estado actual de la producción comunicativa en la nación.

El presente estudio utiliza un importante componente empírico que intenta describir y explicar un objeto de estudio reconocible y 
reconocido por los demás: la producción de un reportaje político en medios masivos de comunicación. Para ello acudimos a un análisis de tipo cualitativo ${ }^{4}$, el cual depende principalmente del análisis visual y los datos verbales, es decir, de la observación y las entrevistas hechas por el investigador.

Con la idea de ubicarnos en un modelo de investigación cualitativa, se considera prudente explicar las tres principales diferencias entre el análisis cualitativo con respecto al cuantitativo ${ }^{5}$. Según Wimmer, la primera de ellas consiste en la percepción de la realidad. Para el investigador cuantitativo, la realidad es objetiva, existe para quién la examina y puede ser contemplada en su totalidad, mientras que para el investigador cualitativo la realidad única no existe, y cada observador crea la realidad formando parte del proceso de investigación. La segunda diferencia trata sobre la visión que los investigadores tienen sobre los individuos particulares. Para el investigador cuantitativo todos los seres humanos son esencialmente similares y busca las características generales para sintetizar sus comportamientos. El investigador cualitativo cree que los seres humanos son básicamente distintos y sus comportamientos no pueden ser generalizados. Y la tercera discrepancia tiene que ver con la explicación investigativa. Los investigadores cuantitativos pretenden establecer leyes generales de comportamiento y explicar muchos aspectos constantes a lo largo de muchas situaciones, mientras que los cualitativos intentan realizar una explicación específica sobre una situación dada. Mientras que los cuantitativos buscan la amplitud, los cualitativos por el contrario buscan la profundidad.

Una vez definido nuestro tipo de investigación, de tipo cualitativo, el paso siguiente consistió en establecer unos criterios de observación, los cuales permitieron fijar categorías y recopilar datos que posteriormente se procesaron y analizaron. Se hizo uso de la observación no participativa $^{6}$, con la intención de no interrumpir las rutinas de trabajo de los periodistas a observar. Para ello, se diseñó una guía de observación, que persiguió una serie de objetivos generales y específicos descritos en el cuadro 2. La guía se utilizó en las fechas y lugares permitidos por los medios de comunicación a observar.

La observación de campo nos proporcionó acceso a la mayoría de los grupos a observar. De las cuatro observaciones realizadas (incluida 
la observación preliminar), tres de ellas lograron hacerse desde "adentro", es decir, desde las propias instalaciones y lugares donde, en el momento, se producía el reportaje. Tan sólo un medio de comunicación no permitió el acceso a sus locaciones de trabajo, lo cual nos condujo a realizar una observación desde "afuera", es decir, que no existió contacto con la producción actual del reportaje, no se observó de forma directa y tan solo se obtuvo información proporcionada por los actores que intervinieron en su producción.

Antes de elaborar la guía de observación se realizó una prueba piloto con una guía provisional. Con el objetivo de someterla a prueba, se comenzó a observar una de las etapas del proceso de producción de reportajes del programa "Miradas" producido por el equipo de Audiovisuales de la Universidad Centroamericana José Simeón Cañas. En primera y única instancia, la guía provisional fue utilizada para observar la recopilación de datos, primera etapa en la construcción de noticias. Durante esta prueba piloto nos encontramos con una serie de dificultades ${ }^{7}$ que nos sirvieron para ser tenidas en cuenta posteriormente durante el desarrollo de la investigación.

\section{Cuadro 2. Objetivos del trabajo de campo}

Objetivo general

Objetivos específicos
- Observar los procesos de producción de noticias / reportajes políticos en los medios de comunicación de masas.

- Conocer las rutinas de producción para la elaboración de noticias / reportajes políticos.

- Describir cada una de las etapas del proceso de producción de la noticia /reportaje político

- Identificar que actores intervienen en cada una de las etapas de construcción de la noticia / reportaje político

- Observar los criterios que convierten un acontecimiento en noticia.

Elaboración propia 
La siguiente actividad consistió en corregir los posibles errores de la guía de observación provisional, teniendo en cuenta nuestra primera experiencia de campo. A pesar de ser conscientes sobre las desventajas que representa la observación directa, las principales dificultades del trabajo de campo fueron las siguientes:

- No se logró de ningún modo tener acceso completo a uno de los medios de comunicación a observar.

- Las jornadas de producción eran demasiado extensas, lo que en algunas ocasiones, impidió su observación total. Las largas jornadas de observación también arrojaban demasiada información que en algunos casos no logró ser capturada en la guía de observación o simplemente no se podía controlar.

- La sola presencia del investigador altera la situación social observable, las rutinas de trabajo pudieron ser levemente modificadas.

- El hecho de ser observados pudo influir en la conducta de los actores que se están analizando. Los periodistas podrían haber cambiado sus comportamientos, y mostrarse diferentes, puesto que su oficio es diariamente cuestionado.

Sin embargo, algunas de estas dificultades lograron ser contrarrestadas a través de una observación controlada y dirigida que se fundamentó en la selección de un grupo de hechos con base en intereses teóricos. Nuestra observación se apoyó en la metodología del Tipo Ideal de Max Weber ${ }^{8}$, la cual pregona que el científico social, más que interesarse por lo común o el promedio de los hechos, se interesa por la interrelación de los aspectos significativos de los hechos, en este caso, los valores que hacen noticiable un acontecimiento. Para responder a nuestro problema de investigación, observamos las rutinas de producción y estudiamos los criterios de selección que utiliza cada uno de los periodistas en el momento de construir la noticia o el reportaje político.

\section{El trabajo de campo: tres experiencias en la construcción de la noticia}

Comenzaremos por describir los procesos de construcción del reportaje en cada uno de los medios de comunicación observados, narrando las diferentes etapas observadas, identificando los actores que 
intervienen en cada una de estas etapas, señalando los motivos que condujeron a tratar determinada información y deteniéndonos en los criterios utilizados por cada uno de los gatekeepers en el momento de manejar el mensaje periodístico. En el cuadro 3, podemos ubicar los datos generales arrojados por el trabajo de campo, sin embargo, iniciaremos por hacer tres descripciones separadas y luego un análisis sobre los valores que predominan y coinciden en el momento de convertir un acontecimiento en reportaje.

\section{Cuadro 3. Información general del trabajo de campo}

\begin{tabular}{|c|c|c|c|}
\hline $\begin{array}{l}\text { Nombre del medio de } \\
\text { comunicación }\end{array}$ & $\begin{array}{l}\text { El Diario } \\
\text { de Hoy }\end{array}$ & $\begin{array}{l}\text { La Prensa } \\
\text { Gráfica }\end{array}$ & CANAL 33 \\
\hline Tipo de medio & Escrito & Escrito & Televisivo \\
\hline Suplemento / programa & Vértice & Enfoques & Emisión Especial \\
\hline $\begin{array}{l}\text { Nombre de noticia / reportaje } \\
\text { político observado }\end{array}$ & $\begin{array}{l}\text { La suerte esta } \\
\text { echada. Se } \\
\text { juegan el todo }\end{array}$ & $\begin{array}{l}\text { Los rostros de } \\
\text { la Asamblea }\end{array}$ & $\begin{array}{l}\text { Las cifras } \\
\text { engañosas }\end{array}$ \\
\hline Fecha de publicación/emisión & $\int_{2003}^{J u n i o ~} 1$ de & $\begin{array}{l}\text { Junio } 1 \text { de } \\
2003\end{array}$ & Junio 8 de 2003 \\
\hline $\begin{array}{l}\text { Tema de noticia/ reportaje } \\
\text { político observado }\end{array}$ & $\begin{array}{l}\text { Candidaturas } \\
\text { presidenciales } \\
\text { de los partidos } \\
\text { políticos } \\
\text { ARENA y } \\
\text { FMLN }\end{array}$ & $\begin{array}{l}\text { Conocer el } \\
\text { grado de } \\
\text { educación de } \\
\text { los diputados } \\
\text { de la Asamblea } \\
\text { Legislativa }\end{array}$ & $\begin{array}{l}\text { Verificar y } \\
\text { corroborar los } \\
\text { datos expuestos } \\
\text { en el discurso de } \\
\text { presidente } \\
\text { después de } 4 \text { años } \\
\text { de gobierno }\end{array}$ \\
\hline $\begin{array}{l}\text { "Gatekeepers" que participaron } \\
\text { en la construcción de la } \\
\text { noticia/ reportaje político } \\
\text { observado }\end{array}$ & $\begin{array}{l}\text { Gerente de } \\
\text { redacción } \\
\text { Editor, } \\
\text { Coordinador } \\
\text { (Redactor), } \\
\text { Diseñador }\end{array}$ & $\begin{array}{l}\text { Gerente de } \\
\text { información, } \\
\text { Editor, } \\
2 \text { Redactoras, } \\
\text { Diseñador }\end{array}$ & $\begin{array}{l}\text { Gerente general } \\
\text { del canal, Jefe de } \\
\text { Prensa del } \\
\text { noticiero del } \\
\text { canal, Productora } \\
\text { (presentadora), } \\
2 \text { Reporteros, } \\
2 \text { Camarógrafos, } \\
\text { Editor }\end{array}$ \\
\hline
\end{tabular}

Elaboración propia. 


\subsection{Experiencia en "Vértice" de El Diario de Hoy (EDH)}

La observación en EDH comenzó al inicio de la semana del 26 de mayo del presente año y culminó a los siete días, con la publicación de la revista dominical "Vértice". No se logró observar absolutamente todo el proceso, en especial la parte donde se materializó el reportaje, sin embargo, tuvimos la posibilidad de tener acceso a todas los espacios y etapas utilizadas por este medio a la hora de producirlo.

La rutina de trabajo inició con una "reunión de edición", donde se agrupó todo el equipo de periodistas que conforman la revista Vértice. En consenso, realizaron una evaluación del último suplemento publicado, se comentaron e hicieron observaciones sobre las publicaciones hechas por la competencia (Revista Enfoques de La Prensa Gráfica) y se definieron los temas a tratar en la revista durante la presente semana. En esta reunión participaron seis periodistas: el editor, el coordinador, dos redactores, una redactora y el fotoperiodista; es justo en esta fase donde se distribuyó la pauta informativa para elaborar el contenido de la revista que posteriormente se publicó el 1 de junio de 2003.

En esta ocasión, el tema de portada no sería de carácter eminentemente político. Sin embargo, se decidió dedicarle al tema político un espacio de dos páginas. El esquema inicial consistió en hacer un análisis sobre las preferencias electorales con base en unas encuestas de opinión realizadas poco tiempo atrás. El enfoque para este mensaje periodístico consistió en resaltar lo poco definidas que se encontraban las candidaturas presidenciales para el 2004. El tema fue asignado al coordinador de la revista, que en este caso, también, hizo las veces de redactor. El posible título de la nota política era: "A la toma del poder".

Una vez definido el tema, el redactor se reunió con el gerente de redacción de $\mathrm{EDH}$ y discutieron, revisaron y replantearon el enfoque que se le dio a la noticia. En esta etapa, se comenzaron a notar los primeros cambios, el enfoque de la nota periodística ahora partiría desde la interpretación de indicadores y estadísticas, de las últimas encuestas de opinión, que estuvieran relacionadas con los precandidatos presidenciales de los partidos políticos FMLN y ARENA. Las valoraciones sobre los temas y personajes implicados en el acontecimiento fueron realizadas por el gerente de redacción del medio (cuadro 4).

\section{7}

La producción de noticias en medios escritos y televisivos de El Salvador 
Cuadro 4. Valoraciones del acontecimiento realizadas por el gerente de información de $\mathrm{EDH}$

\begin{tabular}{|c|c|c|c|}
\hline $\begin{array}{l}\text { Valoración del } \\
\text { "gatekeeper" }\end{array}$ & $\begin{array}{l}\text { Variación en } \\
\text { el sistema }\end{array}$ & $\begin{array}{l}\text { Comunicabilidad } \\
\text { del hecho }\end{array}$ & $\begin{array}{l}\text { Implicación del } \\
\text { destinatario }\end{array}$ \\
\hline $\begin{array}{l}\text { Según las encues- } \\
\text { tas de opinión, se } \\
\text { hacen interpreta- } \\
\text { ciones sobre lo } \\
\text { mal o bien que se } \\
\text { e n c u e n t r a n } \\
\text { posicionados los } \\
\text { precandidatos pre- } \\
\text { sidenciales y se in- } \\
\text { terroga sobre quié- } \\
\text { nes toman las de- } \\
\text { cisiones para las } \\
\text { candidaturas presi- } \\
\text { denciales en el } \\
\text { FMLN y ARE- } \\
\text { NA. Además, se } \\
\text { especula sobre los } \\
\text { posibles compañe- } \\
\text { ros de fórmula } \\
\text { presidencial. }\end{array}$ & $\begin{array}{l}\text { En este caso, la va- } \\
\text { riación es prevista, } \\
\text { puesto que el } \\
\text { acontecimiento se } \\
\text { da basada en un } \\
\text { hecho que ya suce- } \\
\text { dió: las encuestas } \\
\text { de opinión públi- } \\
\text { ca. Sin embargo, } \\
\text { por más previsto } \\
\text { que sea, hay cierto } \\
\text { grado de imprevi- } \\
\text { sión en la medida } \\
\text { que no se han de- } \\
\text { finido oficialmente } \\
\text { los candidatos y } \\
\text { sus posibles com- } \\
\text { pañeros de fórmu- } \\
\text { la. }\end{array}$ & $\begin{array}{l}\text { El acontecimiento } \\
\text { se presta para ser } \\
\text { publicado en for- } \\
\text { ma de noticia; en } \\
\text { este caso, es co- } \\
\text { municable gracias } \\
\text { a que es un hecho } \\
\text { coyuntural y se } \\
\text { ubica en la agenda } \\
\text { de los medios. }\end{array}$ & $\begin{array}{l}\text { El acontecimiento } \\
\text { pretende incidir } \\
\text { sobre el destinata- } \\
\text { rio, de hecho todo } \\
\text { acto comunicativo } \\
\text { lo pretende ser. } \\
\text { En este caso el } \\
\text { acontecimiento } \\
\text { afecta directamen- } \\
\text { te de forma } \\
\text { emotiva o ideoló- } \\
\text { gica, aunque no } \\
\text { tenga incidencia } \\
\text { en la vida cotidia- } \\
\text { na del individuo. }\end{array}$ \\
\hline
\end{tabular}

Elaboración propia basada en Rodrigo Alsina (1989)

Según las encuestas de opinión, se hacen interpretaciones sobre lo mal o bien que se encuentran posicionados los precandidatos presidenciales, se interroga sobre quiénes toman las decisiones para las candidaturas presidenciales en el FMLN y ARENA. Además, se especula sobre los posibles compañeros de fórmula presidencial. En este caso, la variación es prevista, puesto que el acontecimiento se da con base en un hecho que ya sucedió: las encuestas de opinión pública. Sin embargo, por más previsto que sea, hay cierto grado de imprevisión en la medida que no se han definido oficialmente los candidatos y sus posibles compañeros de fórmula $\mathrm{El}$ acontecimiento se presta para ser publicado en forma de noticia; en este caso, es comunicable gracias a que es un hecho coyuntural y se ubica en la agenda de los medios.

$\mathrm{El}$ acontecimiento pretende incidir sobre el destinatario, de hecho todo acto comunicativo lo pretende ser. En este caso, el aconteci- 
miento afecta directamente de forma emotiva o ideológica, aunque no tenga incidencia en la vida cotidiana del individuo.

Una vez reformulado el enfoque, teniendo en cuenta las valoraciones realizadas por el gerente de redacción, se recomendó ampliar la noticia de dos a tres páginas, profundizando en el tema de la democratización al interior de los partidos y sugiriendo diseñar una imagen que ilustrara dicha correlación de fuerzas en el seno de los partidos políticos FMLN y ARENA.

Luego de tener definido el enfoque que se le pretendió dar al reportaje, se procedió a recolectar datos, a través de documentos, encuestas y entrevistas. Se acudió a fuentes institucionales y para el presente caso fueron algunos partidos políticos los que proporcionaron información, también se hizo uso de fuentes espontáneas y confidenciales para complementar dicha información.

La información recolectada empezó a ser procesada en forma de texto. El redactor encargado de la nota periodística comenzó a escribir el texto elaborando un esquema que respondiera al enfoque asignado. En este momento la información comenzó a filtrarse ya que el redactor se encontraba con la libertad de seleccionar la información que él creyó que respondía a su esquema.

Tanto en la redacción como en la edición, los criterios de noticiabilidad más utilizados para la construcción de este reportaje, con base en los efectos y características del acontecimiento, fueron la originalidad y la novedad representadas por una variación en el sistema y la evolución futura de los hechos, generada por las apariciones periódicas que estos acontecimientos pudieran tener sobre todo en temporada preelectoral. También prevaleció la credibilidad como característica del acontecimiento, esto influyó en gran parte por las fuentes confidenciales consultadas para el desarrollo de este reportaje (cuadro 5). 
Cuadro 5. Criterios de selección utilizados en la etapa de redacción y edición por periodistas de $\mathrm{EDH}$

\begin{tabular}{|l|l|l|}
\hline Gatekeepers & $\begin{array}{l}\text { Efectos sobre la sociedad } \\
\text { y otros medios }\end{array}$ & $\begin{array}{l}\text { Cualidades del } \\
\text { acontecimiento }\end{array}$ \\
\hline Redactor & $\begin{array}{l}\text { Novedoso, original, } \\
\text { representa una evolución } \\
\text { futura de los } \\
\text { acontecimientos, importante, } \\
\text { existe proximidad geográfica } \\
\text { y jerarquía de los personajes } \\
\text { implicados }\end{array}$ & $\begin{array}{l}\text { Posee credibilidad, } \\
\text { periodicidad y es } \\
\text { primicia teniendo } \\
\text { en cuenta la } \\
\text { información } \\
\text { proporcionada } \\
\text { por algunas fuentes }\end{array}$ \\
\hline Editor & $\begin{array}{l}\text { Novedoso, original, } \\
\text { evolución futura de los } \\
\text { acontecimientos, importante } \\
\text { y grave y jerarquía de los } \\
\text { personajes implicados }\end{array}$ & $\begin{array}{l}\text { Comprensivo y fácil } \\
\text { de entender, posee } \\
\text { credibilidad y } \\
\text { periodicidad }\end{array}$ \\
\hline
\end{tabular}

Elaboración propia

Después que la información ha sido valorada por el gerente de redacción y por el redactor, el mensaje circuló y entró en la fase de edición. En "Vértice", la edición de cualquier nota informativa tiene que pasar por los siguientes filtros: asignación, edición, corrección y segunda edición. En la asignación, el diseñador establece espacios para fotos y texto, el manejo informativo y gráfico debe ser tenido en cuenta por los periodistas que construyen la noticia, ya que se necesita acomodar la información en los campos asignados. El redactor envía la propuesta de texto al editor, quien se encarga de quitar o agregar información sin olvidar el enfoque que debe tener la noticia, si el texto cumple con los requisitos mínimos de noticiabilidad se le da luz verde y pasa al corrector de estilo, de lo contrario, se devuelve al redactor y pasa a ser corregido o modificado. En esta caso no hubo correcciones ni modificaciones, el texto inicial elaborado por el redactor no sufrió variaciones trascendentales y se mantuvo hasta su publicación. 
Si el gerente de información y el editor aprueban el texto, el redactor trabaja la publicación con el editor fotográfico (en este caso no se utilizaron fotografías) y con el diseñador gráfico. Sin olvidar el enfoque del reportaje se seleccionaron las imágenes que más se acomodaban al mensaje que se pretendía publicar. Una vez escogidas las imágenes, fotos o dibujos, el redactor permaneció atento y dispuesto a realizar cualquier modificación que se le presentará por el camino, ya que los espacios o cajas de texto pueden variar, aumentar o disminuir, según la relevancia que la noticia tenga para la sección, revista, periódico o para el mismo medio. Finalizado el texto en diagramación, se revisó el contenido, y una vez terminada la noticia se envió a producción.

En esta fase, que también hace parte de la construcción del reportaje periodístico, se materializó la información y se comunicó el acontecimiento por medio de su publicación. El proceso en esta etapa fue técnico y consistió en la acción de imprimir la noticia. En esta fase la información se imprimió en una máquina llamada rotativa, la cual utiliza unos cilindros de impresión que giran y rotan en contraria dirección ${ }^{9}$, entre ellos pasa el papel continuo. En la misma máquina el papel es cortado, plegado y contado. Al final, la presentación de la noticia la percibimos de manera escrita.

\subsection{Experiencia con "Enfoques" de La Prensa Gráfica (LPG)}

Con este medio de comunicación no se logró hacer una observación directa del proceso de construcción del reportaje $\mathrm{e}^{10}$. En vista de que no se permitió el ingreso a las instalaciones del medio para observar en el "acto" la producción del mensaje periodístico, optamos por hacer un intento de observación sobre un reportaje que ya se había publicado con anterioridad. Dicho reportaje se escogió, con la condición de que fuera reciente o por lo menos del mes de junio y que fuera de carácter político. En esta ocasión nos encontramos con un reportaje político sobre los nuevos rostros de la Asamblea Legislativa de la nación.

Advertimos que el proceso de producción de la revista semanal "Enfoques, no se logró observar de forma directa. Sin embargo, se hizo un intento por rescatar los principales aspectos de la construcción noticiosa en dicho medio; primero, identificando a los periodis- 
tas que intervinieron en la construcción del mensaje y posteriormente indagándoles por medio de entrevistas sobre las etapas de producción de la nota y los criterios de valoración que utilizaron para desarrollar el reportaje "relativamente" observado.

El tema y enfoque del reportaje fue definido en su totalidad por el editor. En este caso él se convirtió en el responsable de iniciar el desarrollo del acontecimiento para luego transformarlo en reportaje. El editor propuso abordar algún tema que tuviera que ver con la nueva legislatura; según él, con el objetivo que el lector pudiera reflexionar sobre lo que le esperaría de los nuevos diputados de la asamblea legislativa de la nación. El enfoque para este mensaje periodístico era el de investigar las edades, ideologías y preparación académica de los nuevos diputados. Una vez definido el tema y el enfoque, el editor le plantea a la gerente de información cuál será la intención y línea temática de la información, y ella bajo sus propias valoraciones decide si debe o no seguirse trabajando la noticia. En este caso el tema fue: Los rostros de la asamblea legislativa y la gerente dio luz verde al tema.

Al presente mensaje periodístico se le asignó la máxima atención, se constituyó en la nota madre, el tema más importante de la revista, era el tema de portada. La valoración del acontecimiento la hizo el editor, los valores que lo condujeron a seleccionar y prestar atención a los nuevos rostros de la asamblea legislativa se concentraron mayormente en la variación del sistema (cuadro 6).

Teniendo claro el enfoque, posteriormente se le asignó el desarrollo informativo a dos reporteras. Ellas se encargaron de recolectar información, con base en un cuestionario elaborado por una de las reporteras y por el editor (cuadro 7). El cuestionario comprendía 18 preguntas, de las cuales 6 fueron hechas por la reportera y las restantes por el editor. Las preguntas pretendieron elaborar un perfil del diputado actual. Lo interesante detenerse un poco en este cuestionario, ya que se constituyó en un instrumento para recolectar información por parte del propio medio. La mayoría de las preguntas fueron realizadas por el editor y algunas intentaban responder a temas específicos como la representatividad, la ideología, los salarios de los miembros de la asamblea, etc. 


\section{Cuadro 6. Valoraciones del acontecimiento realizados por el editor de la revista "Enfoques" de LPG}

\begin{tabular}{|c|c|c|c|}
\hline $\begin{array}{l}\text { Valoración del } \\
\text { "gatekeeper" }\end{array}$ & $\begin{array}{l}\text { Variación en el } \\
\text { sistema }\end{array}$ & $\begin{array}{l}\text { Comunicabilidad } \\
\text { del hecho }\end{array}$ & $\begin{array}{l}\text { Implicación } \\
\text { sobre el } \\
\text { destinatario }\end{array}$ \\
\hline $\begin{array}{l}\text { Las elecciones de di- } \\
\text { putados son un } \\
\text { tema reciente que se } \\
\text { da en medio de un } \\
\text { clima preelectoral. } \\
\text { Aunque no es un } \\
\text { tema muy importan- } \\
\text { te es interesante sa- } \\
\text { ber acerca de la pre- } \\
\text { paración y forma- } \\
\text { ción académica que } \\
\text { tienen aquellos que } \\
\text { conforma la Asam- } \\
\text { blea Legislativa. } \\
\text { Analizar qué tan } \\
\text { idóneos son los po- } \\
\text { líticos que represen- } \\
\text { tan a la población } \\
\text { salvadoreña. }\end{array}$ & $\begin{array}{l}\text { La variación se da } \\
\text { con relación al } \\
\text { tiempo. Aunque las } \\
\text { elecciones ya suce- } \\
\text { dieron, el aconteci- } \\
\text { miento varía al ob- } \\
\text { tener la categoría } \\
\text { de ser extraordina- } \\
\text { rio, de ir más allá } \\
\text { de lo ordinario y de } \\
\text { lo normal. En este } \\
\text { caso abordar el } \\
\text { tema de la prepara- } \\
\text { ción académica, las } \\
\text { edades y las contra- } \\
\text { dicciones ideológi- } \\
\text { cas de los nuevos } \\
\text { legisladores supone } \\
\text { una ruptura de la } \\
\text { normalidad y por } \\
\text { lo tanto una varia- } \\
\text { ción en el sistema. }\end{array}$ & $\begin{array}{l}\text { El acontecimiento } \\
\text { es comunicable en } \\
\text { la medida que se } \\
\text { trata de un hecho } \\
\text { público, de interés } \\
\text { general para la po- } \\
\text { blación. Aunque } \\
\text { no es un tema de } \\
\text { la agenda política } \\
\text { del momento, es } \\
\text { aprovechado para } \\
\text { ser publicado en } \\
\text { forma de noticia, } \\
\text { teniendo en cuen- } \\
\text { ta que uno de los } \\
\text { temas de la actual } \\
\text { agenda política } \\
\text { son las elecciones. }\end{array}$ & $\begin{array}{l}\text { En este caso, la } \\
\text { implicación pue- } \\
\text { de ser de dos ti- } \\
\text { pos: con implica- } \\
\text { ción directa y no } \\
\text { personal, ya que } \\
\text { no incide en la } \\
\text { vida personal del } \\
\text { individuo, pero } \\
\text { puede afectar las } \\
\text { emociones o pen- } \\
\text { samientos que se } \\
\text { tienen sobre al- } \\
\text { gún diputado de } \\
\text { la Asamblea. Y } \\
\text { con implicación } \\
\text { indirecta donde el } \\
\text { acontecimiento } \\
\text { no afecta al indi- } \\
\text { viduo y es perci- } \\
\text { bido como algo } \\
\text { que le sucede a } \\
\text { otras personas. }\end{array}$ \\
\hline
\end{tabular}

Elaboración propia basada en Rodrigo Alsina (1989). 
Cuadro 7. Esquema del cuestionario elaborado por revista

"Enfoques" de LPG.

\begin{tabular}{|c|c|c|c|}
\hline Gatekeeper & $\begin{array}{c}\text { Cantidad de } \\
\text { preguntas }\end{array}$ & $\begin{array}{l}\text { Principales } \\
\text { preguntas }\end{array}$ & $\begin{array}{c}\text { Objetivos } \\
\text { perseguidos }\end{array}$ \\
\hline Redactora & $\begin{array}{l}\text { Las seis preguntas } \\
\text { elaboradas por la re- } \\
\text { dactora se limitaron } \\
\text { a responder al enfo- } \\
\text { que asignado por el } \\
\text { editor. }\end{array}$ & $\begin{array}{l}\text { Nombre completo, } \\
\text { fecha de nacimiento, } \\
\text { estado civil, último } \\
\text { grado de estudios, } \\
\text { profesión, religión y } \\
\text { deporte favorito. }\end{array}$ & $\begin{array}{l}\text { Obtener informa- } \\
\text { ción general, deter- } \\
\text { minar género, pre- } \\
\text { paración académica } \\
\text { y perfil laboral }\end{array}$ \\
\hline Editor & $\begin{array}{l}\text { Fueron trece las pre- } \\
\text { guntas hechas por el } \\
\text { editor El } 68 \% \text { del } \\
\text { cuestionario fue ela- } \\
\text { borado por él. }\end{array}$ & $\begin{array}{l}\text { Lugar de nacimien- } \\
\text { to (municipio), pri- } \\
\text { mer y último em- } \\
\text { pleo, tiempo de per- } \\
\text { tenecer al partido, li- } \\
\text { bro y figura política } \\
\text { de preferencia, pre- } \\
\text { guntas sobre plazas } \\
\text { o curules en la asam- } \\
\text { blea, salarios y pro- } \\
\text { yectos de ley a im- } \\
\text { pulsar. }\end{array}$ & $\begin{array}{l}\text { Determinar los ni- } \\
\text { veles de representa- } \\
\text { tividad, contrastar } \\
\text { opinión sobre la } \\
\text { circunscripción na- } \\
\text { cional, a partir de } \\
\text { los libros y perso- } \\
\text { najes identificar } \\
\text { ideologías y relacio- } \\
\text { narlas con el parti- } \\
\text { do al que pertene- } \\
\text { cen. }\end{array}$ \\
\hline
\end{tabular}

Luego de definir las preguntas que conformarían los cuestionarios o fichas, se procedió a diligenciarlos. Este trabajo de recolección de datos se hizo de manera personal y demoró un par de días; fue realizado por las dos reporteras asignadas por el editor. Se realizaron 64 fichas de 84 , que es el número de diputados, aunque no se logró interrogar a todos los datos generales como información demográfica, profesional y académica se recolectaron a través de llamadas telefónicas a los mismos diputados o partidos políticos y gracias a la consulta de fuentes espontáneas.

El siguiente paso consistió en tabular y sistematizar la información, de esta manera se podían elaborar las tablas con base en los primeros resultados del cuestionario y se lograban encontrar indicadores con representación estadística. Las primeras tablas fueron aquellas que arrojaban datos como la profesión u oficio, el personaje con el que se identifican y el libro que todo político debe leer, posteriormente se hicieron las tablas sobre la edad y el último nivel de estudios. Es importante resaltar, que el editor propuso trascender hacia el lado "humano" de la información, lo que llevó a complementar el enfoque 
inicial con la cara humana del mensaje informativo, se realizaron entrevistas al diputado más joven, al segundo más viejo (el más antiguo no logró ser entrevistado) y a un diputado que antes de serlo fue agricultor.

Después de sistematizar los cuestionarios en cuadros y tablas, una de las redactoras comenzó a organizar la información a través de la elaboración del texto. El reportaje textualmente se dividió en notas madres, las cuales destacan las grandes líneas del reportaje; notas secundarias, refiriéndose a las historias, perfiles y casos atípicos y finalmente las notas complementarias, que son todas aquellas que proporcionan algún tipo de información relacionada con la noticia. Una redactora elaboró la nota madre, y cuatro notas secundarias, la otra redactora hizo una nota complementaria y realizó unos cuadros informativos. Por su parte, el editor no solo contribuyó en la redacción de varios textos, sino que se encargó de poner los títulos y los párrafos introductorios a cada una de las notas informativas, todo lo anterior en lo que se refiere al esquema textual.

Por otra parte, con lo que tiene que ver con la diagramación, el editor junto con el diseñador discute sobre el tratamiento visual que se la dará a toda la noticia, en este caso, el texto, los recuadros, las tablas, las fotos y los diagramas. Luego el editor gráfico organiza y selecciona la información gráfica, la cual, después de ser revisada queda editada en términos de tratamiento gráfico y textual, luego pasa al corrector de estilo, quien hace las correcciones gramaticales y ortográficas del texto final. Una vez terminado se imprime una copia para la gerente de información, quien tiene la última palabra para hacer observaciones y cambios; para este reportaje no hubo ningún tipo de modificación.

Los criterios de selección utilizados por los periodistas o "gatekeepers" entrevistados son en su mayoría la novedad del acontecimiento, pues no hacía mucho tiempo que las elecciones a la asamblea habían ocurrido y hacer público los perfiles de los nuevos diputados, de personajes importantes del país, se constituía en una primicia. La recolección de información la hicieron ellos mismos a través de entrevistas personalizadas y cuestionarios, este instrumento de recolección de datos se convirtió en la principal fuente de información para el desarrollo del reportaje. Las valoraciones que predominan du- 
rante el desarrollo de la producción noticiosa son las del editor, aunque las redactoras también hacen sus propias valoraciones. En este caso predominaron los criterios de selección utilizados por el editor. Las redactoras coincidieron en su mayoría con los criterios de selección del editor y se limitaron a trabajar la información sin desviarse el enfoque inicial, del enfoque del editor. (Cuadro 8).

Cuadro 8. Criterios de selección utilizados en la etapa de redacción y edición por periodistas de LPG

\begin{tabular}{|l|l|l|}
\hline Gatekeepers & $\begin{array}{l}\text { Efectos sobre la } \\
\text { sociedad y otros medios }\end{array}$ & $\begin{array}{l}\text { Cualidades del } \\
\text { acontecimiento }\end{array}$ \\
\hline Redactora 1 & $\begin{array}{l}\text { Novedoso, importante, } \\
\text { involucra a cantidad de } \\
\text { personas y jerarquía de los } \\
\text { personajes implicados }\end{array}$ & $\begin{array}{l}\text { Comprensivo, fácil de } \\
\text { entender, posee credi- } \\
\text { bilidad y es primicia }\end{array}$ \\
\hline Redactora 2 & $\begin{array}{l}\text { Novedoso, importante y } \\
\text { jerarquía de los personajes } \\
\text { implicados }\end{array}$ & $\begin{array}{l}\text { Comprensivo y fácil de } \\
\text { entender y posee } \\
\text { credibilidad }\end{array}$ \\
\hline Editor & $\begin{array}{l}\text { Novedoso, original, } \\
\text { evolución futura de los } \\
\text { acontecimientos, importante } \\
\text { y jerarquía de los personajes } \\
\text { implicados }\end{array}$ & $\begin{array}{l}\text { Comprensivo y fácil de } \\
\text { entender, periodicidad, } \\
\text { primicia }\end{array}$ \\
\hline
\end{tabular}

Elaboración propia

En suma, cualquier reportaje que se produzca en este medio, tiene que pasar por los siguientes pasos: diseño, redacción, edición, corrección, paginación y publicación. Primero el diseñador crea un archivo, el cual funciona como un espacio de texto y diagramación, son "cajas" sistematizadas en donde se escribirá el texto y se insertarán las imágenes. Este archivo pasa al reportero quien escribe la nota en las cajas de texto delimitadas por el diseñador y posteriormente se le envía al editor, quien hace las primeras correcciones. Más adelante, la información se dirige al departamento de corrección, en donde se hacen las 
segundas correcciones; allí, una vez la información es corregida, se lleva a paginar, en esta fase se hacen los ajustes definitivos de diseño para imágenes y texto, y finalmente se crea una copia digital. La publicación de la noticia se hace a través de la rotativa ${ }^{1 i}$. Por último, el mensaje informativo es difundido de forma escrita.

\subsection{La experiencia en "Emisión Especial” de Canal 33}

El trabajo de campo en este medio es de gran utilidad para nuestra investigación, principalmente por dos razones: en primer lugar, porque fue el último en realizarse, lo que nos llevó a perfeccionar nuestras tácticas de observación, y en segunda instancia porque nos permitió acercarnos al proceso de producción de reportajes políticos en televisión, los cuales mantienen diferencias significativas con los de tipo escrito. La principal diferencia radica en el tiempo que la información está disponible para el público, mientras que en un periódico se cuenta con la ventaja de observar la información detenidamente, de "re-leer" el mensaje; en la televisión el mensaje se emite rápidamente, difícilmente se cuenta con la opción de ser repetido y "re-analizado". En la televisión, los mensajes periodísticos son menos analíticos; sin embargo, esa desventaja se compensa a la hora de ser más veloces en el momento de comunicar el mensaje. El aprovechar con astucia "esos" cortos espacios de tiempo hace que unos medios de comunicación sean más efectivos que otros.

La producción informativa del programa observado comenzó el primer día de la semana con una reunión entre la productora del programa, un reportero, una reportera y una camarógrafa. En dicho encuentro se realizó una evaluación del último programa emitido, se hicieron las observaciones pertinentes y luego se procedió a proponer el tema para trabajar durante el transcurso de la semana. En esta ocasión surgieron varios temas: unos eran de agenda pública, otros de interés sociocultural y otros eran temas que ya se habían trabajado y requerían de una continuación. El mismo día, en horas de la tarde se agrupó todo el equipo de periodistas para hacer la reunión de pauta, allí asistieron el director general del canal, el jefe de prensa del noticiero del mismo, la productora del programa (también hace las veces de presentadora del mismo), dos reporteros, una reportera, un camarógrafo y una camarógrafa. En dicha reunión de pauta, el gerente general del

\section{7}

La producción de noticios en medios escritos y televisivos de El Salvador 
canal hizo las observaciones correspondientes sobre el último programa, evaluó cada reportaje y con la participación de algunos (existen opiniones muy influyentes, como la del jefe de prensa del noticiero del canal) se asignó el tema para trabajar en la semana. Esta vez, el tema a trabajar fue el discurso del presidente salvadoreño Francisco Flores. Era un tema actual, apenas había sido emitido un día antes. El enfoque para el reportaje lo orientó el gerente general del canal, se trataba de corroborar y comprobar hasta qué punto eran ciertos o falsos los datos estadísticos sobre resultados en educación y vivienda, expuestos en el discurso del presidente Flores en su cuarto año de gobierno ${ }^{12}$.

Para definir el tema se tuvieron en cuenta varios elementos, entre ellos que era un acontecimiento coyuntural y actual y que estaba en la agenda pública y de los medios. Para el gerente del canal, las cifras presentadas en el discurso del presidente eran exageradas y lejanas a la realidad. Inicialmente, se propuso investigar la veracidad de las cifras en educación y salud, pero se desechó la segunda opción ya que consideró difícil conseguir datos que comprobaran la inverosimilitud del discurso en materia de salud, por tanto, propuso el tema de vivienda; en primer lugar, porque se relacionaba con el tema de educación en aspectos de construcción; segundo, porque también presentó cifras exageradas y tercero, porque las fuentes de las que disponían les permitía hacer un mejor trabajo investigativo. El jefe de prensa propuso buscar fuentes técnicas, esa idea fue apoyada por el gerente del canal y uno de los reporteros, para este caso el gerente del canal y jefe de prensa sugirieron consultar fuentes propias del medio, fuentes institucionales y expertas en materia de construcción. Las valoraciones del acontecimiento fueron realizadas en su gran mayoría por el gerente general del canal, aunque también se observó la importante incidencia de las valoraciones del jefe de prensa del noticiero del canal, sin embargo, se notó en esta reunión de pauta las escasas valoraciones hechas por parte del resto del equipo de periodistas (Cuadro 9). 


\section{Cuadro 9. Valoraciones del acontecimiento realizadas por \\ Gerente general del el Canal 33}

\begin{tabular}{|c|c|c|c|}
\hline $\begin{array}{c}\text { Valoración del } \\
\text { Gatekeeper }\end{array}$ & $\begin{array}{l}\text { Variación en } \\
\text { el sistema }\end{array}$ & $\begin{array}{c}\text { Comunicabilidad } \\
\text { del hecho }\end{array}$ & $\begin{array}{l}\text { Implicación } \\
\text { sobre el } \\
\text { destinatario }\end{array}$ \\
\hline $\begin{array}{l}\text { Se propone hacer } \\
\text { una investigación } \\
\text { más completa sobre } \\
\text { datos del discurso } \\
\text { del presidente. Se- } \\
\text { gún propia interpre- } \\
\text { tación los resultados } \\
\text { son exagerados. } \\
\text { Considera que el } \\
\text { discurso de cuarto } \\
\text { año de gobierno es } \\
\text { propagandístico y } \\
\text { sólo muestra aspec- } \\
\text { tos positivos, lo } \\
\text { que conduce a reali- } \\
\text { zar un reportaje que } \\
\text { verifique datos y ex- } \\
\text { plique de dónde } \\
\text { provienen los recur- } \\
\text { sos para la construc- } \\
\text { ción de escuelas y } \\
\text { viviendas. }\end{array}$ & $\begin{array}{l}\text { Aunque es normal y } \\
\text { de esperarse el dis- } \\
\text { curso del presiden- } \\
\text { te Flores en su } \\
\text { cuarto año de go- } \\
\text { bierno, es conside- } \\
\text { rado como impre- } \\
\text { visto y extraordina- } \\
\text { rio los resultados } \\
\text { exagerados expues- } \\
\text { tos en el mensaje } \\
\text { discursivo. La varia- } \\
\text { ción se da en térmi- } \\
\text { nos de "magnitud", } \\
\text { es decir el número } \\
\text { de escuelas y vivien- } \\
\text { das construidas no } \\
\text { son creibles. La es- } \\
\text { casa confiabilidad } \\
\text { en los datos oficia- } \\
\text { les genera la varia- } \\
\text { ción del sistema. } \\
\end{array}$ & $\begin{array}{l}\text { Por tratarse de un } \\
\text { tema de interés ge- } \\
\text { neral y nacional, el } \\
\text { acontecimiento ad- } \\
\text { quiere valor para } \\
\text { ser comunicado al } \\
\text { público. Además, } \\
\text { por el hecho de ser } \\
\text { un discurso del pre- } \\
\text { sidente dirigido a la } \\
\text { nación, el aconteci- } \\
\text { miento se presta } \\
\text { para ser investigado } \\
\text { y comunicado al } \\
\text { público. En este } \\
\text { caso el tema es de } \\
\text { la agenda política y } \\
\text { el medio se encarga } \\
\text { de darle la impor- } \\
\text { tancia necesaria. }\end{array}$ & $\begin{array}{l}\text { La implicación } \\
\text { puede ser directa } \\
\text { y personal, en la } \\
\text { medida que el in- } \\
\text { dividuo se sienta } \\
\text { víctima por los } \\
\text { posibles engaños } \\
\text { del discurso del } \\
\text { presidente. Tam- } \\
\text { bién puede haber } \\
\text { una implicación } \\
\text { directa y no per- } \\
\text { sonal, mientras el } \\
\text { hecho no incida } \\
\text { en la vida cotidia- } \\
\text { na del individuo, } \\
\text { pero incida en el } \\
\text { pensamiento que } \\
\text { se tiene sobre el } \\
\text { presidente; o tam- } \\
\text { bién el individuo } \\
\text { no se siente afec- } \\
\text { tado y le es indi- } \\
\text { ferente el suceso. }\end{array}$ \\
\hline
\end{tabular}

Elaboración propia, basada en Rodrigo Alsina (1989).

Luego de tener claro el enfoque que se la daría al reportaje, el tema se le asignó a un reportero y una reportera. Ellos comenzaron por tomar nota de las fuentes a consultar sugeridas por el gerente y el jefe de prensa del canal y posteriormente se reunieron para determinar qué preguntas deberían de hacerles a los entrevistados. Las preguntas se centraron en indagar acerca del número de construcciones de escuelas y viviendas, cómo fue su financiamiento, cuál era la calidad de dichas construcciones, si eran permanentes o temporales, y qué organizaciones no gubernamentales hicieron parte del programa de construcción. La idea de las entrevistas aparte de verificar datos para probar que el 
presidente mintió en su discurso, consistió en aclarar que el acelerado aumento de construcciones en gran parte se hicieron gracias a la ayuda extranjera como consecuencia de las pérdidas ocasionadas por los terremotos del año 2001.

Aunque el enfoque del reportaje lo definió el gerente general del canal, el resto del equipo de periodistas usó unos criterios de selección, los cuáles estaban implícitos en esta rutina de trabajo y fueron utilizados para el proceso de construcción del reportaje. La mayoría de los periodistas coincidió con que el discurso del presidente, era un acontecimiento importante y grave, además, representaba una evolución futura de los acontecimientos y era fácil de entender; todos pensaron que el discurso no tenía ningún tipo de credibilidad y algunos valoraron el acontecimiento como sensacionalista en la medida que era exagerado e increíble (cuadro 10). Todos estos criterios de selección coincidieron en gran parte con lo expresado en la reunión de pauta, por parte del gerente general del canal.

\section{Cuadro 10. Criterios de selección utilizados por periodistas del canal 33}

\begin{tabular}{|l|l|l|}
\hline Gatekeepers & \multicolumn{1}{|c|}{$\begin{array}{c}\text { Efectos sobre la sociedad y } \\
\text { otros medios }\end{array}$} & \multicolumn{1}{|c|}{$\begin{array}{c}\text { Cualidades del } \\
\text { acontecimiento }\end{array}$} \\
\hline Jefe de prensa & $\begin{array}{l}\text { Evolución futura de los acontecimientos, } \\
\text { importante, grave, proximidad geográfi- } \\
\text { ca, y magnitud (cantidad de personas). }\end{array}$ & $\begin{array}{l}\text { Comprensivo, fácil de en- } \\
\text { tender, periodicidad, sensa- } \\
\text { cionalista. }\end{array}$ \\
\hline Productora & $\begin{array}{l}\text { Evolución futura de los acontecimientos, } \\
\text { importante, grave, jerarquía de los per- } \\
\text { sonajes implicados. }\end{array}$ & $\begin{array}{l}\text { Comprensivo, fácil de en- } \\
\text { tender, periodicidad. }\end{array}$ \\
\hline Reportero & $\begin{array}{l}\text { Novedoso, evolución futura de los acon- } \\
\text { tecimientos, importante, proximidad geo- } \\
\text { gráfica, magnitud (cantidad de personas } \\
\text { y lugares), jerarquía de los personajes im- } \\
\text { plicados. }\end{array}$ & $\begin{array}{l}\text { Comprensivo, fácil de en- } \\
\text { tender, periodicidad, sensa- } \\
\text { cionalista. }\end{array}$ \\
\hline Reportera & $\begin{array}{l}\text { Importante, magnitud (cantidad de per- } \\
\text { sonas y lugares), jerarquía de personajes } \\
\text { implicados }\end{array}$ & $\begin{array}{l}\text { Comprensivo, fácil de en- } \\
\text { tender, breve. }\end{array}$ \\
\hline Camarógrafo & $\begin{array}{l}\text { Original, importante, grave, magnitud } \\
\text { (personas), jerarquía personajes implicados }\end{array}$ & $\begin{array}{l}\text { Periodicidad y sensaciona- } \\
\text { lista. }\end{array}$ \\
\hline Camarógrafa & $\begin{array}{l}\text { Evolución futura de los acontecimientos, } \\
\text { importante, grave, magnitud (personas y lu- } \\
\text { gares), jerarquía de personajes implicados. }\end{array}$ & Breve, sensacionalista. \\
\hline
\end{tabular}

Elaboración propia. 
A través de entrevistas personalizadas cada periodista inició su propia recolección de datos, el reportero trabajó el tema de vivienda y la reportera el de educación. En cada entrevista los reporteros iban acompañados de un camarógrafo o una camarógrafa, ellos se encargaban de registrar completamente las entrevistas y captar algunas imágenes de apoyo que complementaran el mensaje informativo ${ }^{13}$. Se entrevistaron a fuentes institucionales, espontáneas y especializadas, con el objetivo de confrontar datos, contrastar opiniones y demostrar la ambigüedad del discurso presidencial. Una vez realizadas y grabadas todas las entrevistas, cada reportero las revisó detenidamente y comenzó a seleccionar información que respondiera al enfoque de la noticia. En esta fase, los reporteros hacen las veces de editores, comenzando a seleccionar la información que ellos consideran más relevante para la construcción del reportaje político. A esta técnica selectiva de información se le conoce, en éste medio, como "visualización".

Después de visualizar las entrevistas, se comienza a construir el guión. Cada reportero hizo una reselección de lo que había visualizado, es decir, volvió a seleccionar información de lo que ya había seleccionado, esta vez, para insertarla en el guión. A la información visual, se le suma información auditiva, los reporteros graban sus voces con base en un texto que ellos mismos escriben, comentando la información investigada y relacionándola con las imágenes que complementaron el mensaje informativo. Cada reportero hizo un bosquejo del tratamiento textual y visual del reportaje, y sin olvidar el enfoque de la noticia arman y estructuran el manejo audiovisual del mensaje periodístico, luego la productora lo revisa y como periodista hace las observaciones y revisiones del caso.

La productora, aparte de encargarse del manejo logístico y financiero para la elaboración del programa, también hace las veces de presentadora. La presentación también exige un guión, que también elaboró la productora del programa. En esta noticia, el guión estaba conformado por tres bloques, cada bloque tiene una entrada y una salida. Estos se ubican en el guión final del programa. Los bloques sirven para introducir el programa, hacer comentarios respecto a la noticia y finalmente despedir la emisión.

La edición es un proceso largo y agotador. El reportero, junto con el editor de imágenes y sonido, y la supervisión esporádica de la productora, comenzó a insertar y organizar en una sola memoria la pre-

\section{1}

La producción de noticios en medios escrilos y televisivos de El Salvador 
sentación del programa (los tres bloques), las imágenes de apoyo, los segmentos de las entrevistas visualizadas, y las voces de los reporteros. En otras palabras, se materializó la información, la cual, ya ha sido seleccionada y pre-editada por los reporteros y la productora. El editor trabajó sobre un guión que especificaba el manejo de imagen y sonido. Una vez editado todo el programa, se grabó en un casete el cual se lleva al equipo de producción del canal, quien se encarga de emitirlo en la fecha y la hora correspondiente.

\section{Conclusiones y consideraciones finales}

El trabajo de campo es el resultado directo de la aplicación de una serie de estudios sobre la producción de la noticia o newsmaking, a un caso específico que es la construcción de reportajes políticos en medios de comunicación escritos y televisivos de El Salvador. Como parte de un estudio cualitativo, no podemos generalizar sobre un patrón común en los procesos de producción, sin embargo, sí podemos afirmar que tanto en "Vértice" de EDH, como en "Enfoques" de LPG y "Emisión Especial" del Canal 33, la construcción de los reportajes pasa por una serie de rutinas de producción establecidas por la misma profesión o el propio medio.

Las rutinas de producción de cada medio observado fueron diferentes. La forma de producir noticias escritas diverge con la manera de producir noticias televisivas. Incluso, en las mismas formas de producción escrita existen diferencias: la organización del trabajo, la utilización de locaciones, los avances tecnológicos y las funciones de los periodistas difieren en los dos medios escritos observados. Sin embargo, la principal diferencia entre producción escrita y televisiva se encuentra en la manera en que nuestros sentidos captan el mensaje; en la comunicación escrita, el tratamiento del mensaje es textual y gráfico; mientras que en la televisiva el tratamiento del mensaje es audiovisual; ello, por supuesto, sin olvidar las diferencias en materia de producción y técnicas de publicación o realización del mensaje. Aunque perezca una conclusión obvia, es importante tener en cuenta esta diferencia a la hora de analizar los efectos del mensaje periodístico, el tipo de público a quien va dirigido y el modo de comunicarlo, ya sea por vía impresa o electrónica. 
En este estudio, aparte de identificar a los periodistas o gatekeepers que intervienen en la construcción del mensaje, se logró observar los criterios utilizados por cada uno de ellos en el momento de seleccionar la información que formaría parte del reportaje. Dentro de cada medio hay una estructura organizada de capacidades de poder para tomar decisiones sobre los temas seleccionados. No cabe duda, que unos periodistas poseen mayor rango que otros, y al momento de tipificar los acontecimientos impera la valoración realizada por los periodistas de mayor jerarquía. Sin embargo, esto no significa que el resto de periodistas no utilicen sus propios criterios de valoración, siendo así que ellos, independientemente de su posición, valoran, seleccionan e interpretan los acontecimientos bajo su propio criterio periodístico, sin desobedecer a la rutina de trabajo preestablecida por el superior o por el medio de comunicación.

La organización del trabajo es de vital importancia para el desarrollo informativo de los medios de comunicación. No fue difícil darse cuenta de la acumulación de trabajo y la carrera contra el tiempo que semana a semana tiene el periodista. Se pudo observar que las limitaciones de los recursos humanos y técnicos reflejaron una de las principales necesidades en la producción de la noticia. Si sabemos que existe una organización del trabajo en torno a un producto común que es la noticia, debemos preguntarnos hasta qué punto estas insuficiencias de personal y de medios técnicos influyen para que la función del periodista se relacione más con el producto informativo, que con la realidad de los hechos.

Las rutinas de producción observadas en los medios EDH, LPG y Canal 33 se resumen en las siguientes etapas: a) recopilación y selección, b) redacción y edición; y c) publicación o presentación. La primera etapa mostró la mutua relación que existe entre las fuentes y los medios de comunicación. En el EDH, las fuentes confidenciales y espontáneas fueron fundamentales para el desarrollo y enfoque de la noticia, mientras que en LPG la recopilación de datos se hizo a través de entrevistas personalizadas y cuestionarios, esta técnica de recolección de datos se convirtió en su principal fuente de información. Por su parte, en el Canal 33 la relación con las fuentes fue bastante cordial, se consultaron fuentes oficiales, institucionales y especializadas las cuáles permitieron contrastar opiniones que respondieron gratamente al enfoque inicial de la noticia. 
La fase de redacción y edición se caracterizó por estar íntimamente ligada. El periodista hace de las veces de redactor y editor, y en algunas ocasiones cumple también con otras funciones. En el caso de EDH, el coordinador de la revista donde se publicó el reportaje, redacta y edita su propia publicación antes de enviarla al editor, quien también hace las correcciones y ediciones pertinentes. El editor está al tanto de todo lo que se va a publicar textual o gráficamente y tiene la autoridad de suprimir o añadir información. En LPG, la redacción y edición fue controlada en su gran mayoría por el editor. A pesar de que una de las reporteras escribió las líneas más importantes de la noticia, la iniciativa de las periodistas fue baja, el editor propuso y manejó la intencionalidad de casi toda la noticia. La edición nunca descuidó su enfoque inicial, los textos, las fotos y los diagramas siempre estuvieron bajo la supervisión del editor. Por otro lado, en el canal 33 la redacción y edición van casi de la mano, cada reportero se encarga de redactar y editar la información que luego será reeditada en el guión del programa, es decir, que los reporteros cumplen dentro de su rutina de trabajo con esta doble función. La productora también hace parte de la redacción y edición, coordina y apoya el trabajo de edición, y redacta los comentarios que se hacen sobre la noticia durante la emisión del programa. En suma, todos los periodistas observados seleccionan información bajo sus propias valoraciones, y eso los convierte en editores de la información.

La publicación o presentación también hace parte de las rutinas de producción de reportajes. Aquí el acontecimiento se hace tangible, se materializa para poder ser percibido por nuestros sentidos. Tanto en EDH como en LPG, la información se imprime y se publica. Esta fase no se logró observar. En cambio, la materialización de la información en el Canal 33, se logró ver desde su inicio hasta su final. En vista de que el programa Emisión Especial es pregrabado, se permite registrar el mensaje informativo en un "vídeo", el cual se emite en la fecha y hora señalada de programación por el canal. La presentación del programa dura 30 minutos aproximadamente y a diferencia de las presentaciones escritas su difusión es mucho más rápida.

En síntesis, la construcción de noticias en medios escritos y televisivos exige una serie de rutinas de producción. Estas rutinas se complementan con los criterios de selección utilizados por cada uno de los periodistas o gatekeepers que valoran los acontecimientos que 
posteriormente se convierten en noticia. Cada uno de estos gatekeepers actúa como un filtro en la línea comunicacional que existe entre el acontecimiento y la noticia; y su función consiste en detener o dejar circular la información. Bajo los resultados observados, podemos aseverar que la información es interpretada, ampliada, suprimida o modificada por cada uno de los "gatekeepers", que independientemente de las valoraciones que haga sobre los hechos, los acontecimientos obligatoriamente tienen que atravesar una serie de etapas y filtros implícitos en las rutinas de producción para llegar a ser reportaje político.

\section{REFERENCIAS BIBLIOGRÁFICAS}

Carles Tomás. "Metodología de la producción e Investigación", Investigación científica de la comunicación en http://www.iua.upf.es/ 〜 ctomas/master_t1.htm http://www.iua.upf.es/ ctomas/ master_t1.htm.

Hekman, Susan J. "Max Weber, el tipo Ideal y la teoría social contemporánea”, McGraw Hill, México, D.F., 1999.

López de Zuazo, Diccionario de Periodismo, Pirámide, Madrid, 1990.

Luzón, Virginia. "Nuevas tecnologías, nuevos medios profesionales", en Revista Latina de Comunicación Social, número 7, La Laguna (Tenerife), julio de 1998, http://www.lazarillo.com/latina/a/ 73lu.htm. http://www.lazarillo.com/latina/a/73lu.htm.

Martín Sabarais, Rosa. Un estudio cualitativo de la producción de noticis, presentado al II Coloquio Brasil-Estado Español de Ciencias da Comunicación, Santiago de Compostela, 1998, en http:// www.ull.es/publicaciones/latina/argentina2000/plagiado.

Martini, Stella. "Periodismo, noticia y noticiabilidad", Ed. Norma, Buenos Aires, 2000 en http://www.nombrefalso.com.ar/materias/apuntes/pdf/martini.pdf

Rodrigo Alsina, Miquel. Los modelos de la comunicación, Ed. Tecnos. Madrid, 1989.

Rodrigo Alsina, Miquel. La construcción de la noticia, Ed. Paidós, Barcelona, 1993.

Ruiz Olabuénga, José Ignacio, Metodología de la investigación cualitativa, Universidad de Deusto, Bilbao, 1999. 
Saperas, Eric. Introducción a las teorías de la comunicación, Portic. Barcelona, 1992.

Wimmer R. Dominick. La investigación científica de los medios de comunicación, Bosch, Barcelona, 1996.

\section{NOTAS}

1. El trabajo se enmarca en la línea de investigación sobre Comunicación Política que desarrolla la Maestría en Ciencia Política de la UCA. Para la realización de este artículo se contó con la valiosa colaboración y aporte de la periodista Rosarlin Hernández.

2. La expresión académica de la investigación sobre los medios de comunicación se logra sintetizar en La Teoría de la Comunicación (Rodrigo, M., 1989 y Saperas, E., 1992). El objeto de estudio de esta teoría se concentra en la comunicación de masas y el proceso de formación de la opinión pública, no obstante los nuevos modelos de investigación comunicativa centran su atención en los procesos productivos, la intervención tecnológica e interpretación del mensaje periodístico, haciendo posible que el investigador pueda observar, comprender y explicar las actuales tendencias de la comunicación social.

3. La noticia, más que la divulgación de un hecho, es la construcción periodística de un acontecimiento, cuyas características y efectos sobre la sociedad la ubican públicamente para su reconocimiento (Martini, 2000).

4. En Metodologia de la Producción e Investigación, según Carles Tomás, las modalidades de investigación comunicativa se pueden resumir en cinco tipos: 1. Investigación cualitativa: comprende y explica (argumentativamente) el objeto de estudio, considerando su contexto político, histórico, tecnológico y socioeconómico. Se desarrolla mediante la observación, las entrevistas, el análisis documental, etc. 2. Investigación cuantitativa: describe, contextualiza y explica con técnicas estadísticas el objeto de estudio (se generalizan comportamientos con base en casos particulares). Se persigue que las muestras sean representativas. 3. Investigación pura: Innovación y elaboración de técnicas, procedimientos de análisis y creación de paradigmas aceptados por la comunidad científica. 4. Investigación experimental: simular, estudiar y contrastar un segmento de la realidad en un contexto controlado por el investigador. 5. Investigación aplicada: identificar, priorizar, planificar y aplicar aspectos de la comunicación en un sector social determinado.

5. Wimmer, 1996.

6. "El investigador no participa por completo en la vida social del grupo al que observa, no es un participante al completo, sino que participa como observador. Tanto el investigador, como los observados saben y son concientes de los objetivos y planes del investigador, cosa que no sucede cuando ese participa al completo" (Ruiz O., 1999).

7. La primera dificultad con la que nos encontramos fue el manejo del tiempo. La producción de reportajes y periodismo investigativo exige una extensa dedicación. La observación resulta ser larga y agotadora. 
8. El tipo ideal en la metodología de Max Weber esta noticia sostiene que todo análisis científico social debe mantener dos etapas. Primero, la creación de una categoría de los hechos, los cuales son utilizados para responder al problema investigado; y segundo, la selección de un segmento particular de esos hechos, los cuáles son estudiados con base en el interés particular del investigador. En este caso, la categoría de los hechos son las diferentes etapas del proceso de producción de la noticia, y el segmento para analizar de esos hechos son los criterios de selección de información utilizados en cada una de las etapas investigadas. (Hekman, S. 1999).

9. Ver definición de "rotativa", en Diccionario de periodismo, López de Zuazo, 1990.

10. Según las políticas internas del medio, no se permite la entrada a personal ajeno al periódico. A pesar de la insistencia por parte nuestra sobre los objetivos científicos de nuestra investigación, la respuesta nunca fue positiva por parte de la gerencia de información. No obstante, gracias a la colaboración de algunos periodistas del medio, se logró recopilar datos y experiencias que enriquecieron nuestro estudio.

11. Máquina de imprimir sobre el papel continuo por el sistema de cilindro contra cilindro, lo cual permite imprimir a la vez el anverso y reverso de una hoja. La cuchilla cortadora va separando las páginas y la máquina plegadora va formando los cuadernillos con la misma velocidad de impresión. Diccionario de periodismo, López de Zuazo, 1990.

12. La reunión de pauta es parte de una de las fases de la construcción de la noticia. Aquí se comienza a observar cómo se selecciona la información, cuáles temas se van a tratar y cuáles no, cómo se define el enfoque de la noticia y qué fuentes se pueden consultar.

13. Aparte de grabar las entrevistas, los camarógrafos registraron imágenes que permitieron mostrar el rostro humano del reportaje, los reporteros le dicen al camarógrafo sobre las imágenes que necesitan y ellos se encargan de capturarlas visualmente. Para este caso se tuvieron en cuenta experiencias e historias particulares de individuos afectados por los terremotos de 2001. 